\title{
A STUDY SHOWING THE EFFECTIVENESS OF IRBESARTAN IN THE TREATMENT OF BENIGN PROSTATIC HYPERPLASIA
} BY

\author{
Zeina Hussein, Reem N. Abou El-Naga, Mai F. Tolba, Ebtehal El-Demerdash \\ FROM \\ Department of Pharmacology and Toxicology, Faculty of Pharmacy, Ain Shams \\ University, Abbasia, Cairo, Egypt
}

\begin{abstract}
Angiotensin receptor blockers (ARBs) were developed for the treatment of high blood pressure to antagonize increased angiotensin II-dependent vasoconstriction. The aim of our study was to evaluate whether irbesartan had beneficial effects on the reduction of prostate weight in a rat model of benign prostatic hyperplasia (BPH). Benign prostatic hyperplasia was induced by subcutaneous injections of testosterone enanthate for four weeks in albino rats, and rats were treated with or without oral doses of irbesartan $(10,20$ and $40 \mathrm{mg} / \mathrm{kg})$ for five consecutive days per week for four successive weeks during BPH induction. After 4 weeks, the protein abundance of nuclear factor kappa-B was assessed immunohistochemically in the prostate tissue taken from the different treatment groups. The irbesartan $(40 \mathrm{mg} / \mathrm{kg})$-treated group showed a significant decrease in prostate weight, prostate index and nuclear factor kappa-B abundance compared to the non-treated BPH group. These results show that irbesartan is effective in decreasing the weight and proliferation of the prostate, and suggest that irbesartan may be an effective treatment for BPH.
\end{abstract}

\section{Introduction}

Benign prostatic hyperplasia $(\mathrm{BPH})$, is a non-cancerous enlargement of the prostate gland. The incidence of BPH increases linearly with aging and it has become a generally observed major disease among older males. An estimated 50\% of males show histological evidence of BPH by the age of 50 years and $80 \%$ by the age of 70 years (O'Malley et al. 2009; Paolone 2010).

Benign prostatic hyperplasia involves hyperplasia of prostatic stromal and epithelial cells, resulting in the formation of large, fairly discrete nodules in the periurethral region of the prostate. The enlarged prostate gland interferes with the normal flow of urine resulting in lower urinary tract symptoms (LUTS), including urinary hesitancy, frequent urination, urgency, thin urine flow and urinary retention (Roehrborn 2011; Oh 2013). These symptoms greatly affect the physical and mental health of patients, as well as their quality of life.

Delayed treatment is likely to cause a number of severe complications, including bleeding from the prostate, recurrent infections, renal stones and even kidney failure (Pawlicki et al. 2004).

The renin-angiotensin system (RAS) is a hormonal cascade that is important in regulating pressure and cardiovascular homeostasis (Peach 1977; Johnston 1990). Indeed, hyperactivity of the RAS has been implicated in the development of hypertension and other cardiovascular disorders (Nicholls et al. 1998). Angiotensin II (Ang II) is the principal effector peptide of the RAS system (Johnston 1990). Locally- 
generated Ang II facilitates the release of noradrenaline from sympathetic nerves of the rat prostate, these data provide direct evidence to support the functional role of local RAS in modulating sympathetic activity in the prostate, which may have important implications for the pathophysiology of BPH (Fabiani et al. 2001) .

Strong evidence showed that BPH is associated with chronic inflammation

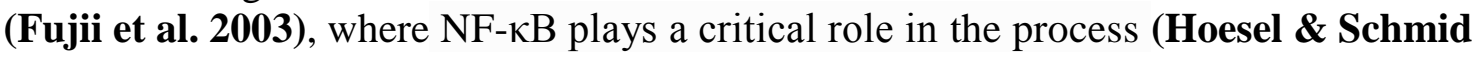
2013). Peroxisome proliferator-activated receptor gamma (PPAR $\gamma$ ) was found to be an important regulator of cell differentiation, proliferation in other types of stromal cells (macro-phages, endothelium and smooth muscles) (Barak et al. 1999; Rosen \& Spiegelman 2001; Tontonoz et al. 1994) as well as in prostate (Arruzazabala et al. 2007; Baeuerle \& Baltimore 1996; Barry 2001). Loss of PPAR $\gamma$ function in the prostate leads to a number of consequences; including wide spread inflammation and hyperplastic growth (Baeuerle \& Baltimore 1996). In addition, PPAR $\gamma$ ligands were shown to induce an anti-inflammatory response where they reduce recruitment of neutrophils, monocytes and eosinophils (Shappell et al. 2001). Therefore, PPAR $\gamma$ is an attractive target for manipulation in therapeutic strategies to treat prostatic disease. Irbesartan, an ARB , was shown to act as PPAR $\gamma$ ligand in vitro (Jiang et al. 2010) that interestingly possesses an anti-inflammatory action (Standiford et al. 2005).

Accordingly, the aim of this study was to evaluate whether irbesartan had beneficial effects on the reduction of prostate weight in a rat model of benign prostatic hyperplasia (BPH). Besides, its effect on the NF-kB expression in prostate tissue was assessed.

\section{Materials and Methods:}

\section{Drugs and chemicals:}

Irbesartan was purchased from shaanxi huike Biotechnology CO. (ltd, china), tween $80 \%$ was purchased from Sigma Chemical Co. (St. Louis, MO, USA). Testosterone enanthate; (Steroid S.P.A, Cologno Monzese (MI), Italy) was kindly supplied by (Chemical Development Industries Co. (CID), Cairo, Egypt). All other chemicals were of the highest available analytical grade.

\section{Animals}

Animals handling and treatment protocol has been approved by Bioethical and Research Committee of Ain Shams University, Cairo, Egypt. Male Sprague-Dawley rats, (150-200g) aged 10 weeks, were purchased from Nile Co. for Pharmaceutical and Chemical industries, Cairo, Egypt. Rats were housed in an air-conditioned atmosphere, at a temperature of $25^{\circ} \mathrm{C}$ with alternatively 12 hour light and dark cycles. They were kept on a standard diet and water ad libitum. After 7 days of acclimatization, they were randomly distributed into experimental groups.

\section{Experimental design}

Rats were randomly divided into five groups eight animals each and treated for five consecutive days per week for four successive weeks as follow; the first group (control group) was given $(2.5 \mathrm{ml} / \mathrm{kg}$ ) of mixture of tween $80 \%$ and saline (1:9) which 
was used as a vehicle for irbesartan through oral gavage and $(1 \mathrm{ml} / \mathrm{kg})$ olive oil subcutaneously (s.c.). The second group was given irbesartan vehicle and $3 \mathrm{mg} / \mathrm{kg}$ testosterone dissolved in olive oil S.C. to induce BPH (Youn et al. 2017). The third, the forth and the fifth groups were given an oral dose of irbesartan $(10 \mathrm{mg} / \mathrm{kg}, 20 \mathrm{mg} / \mathrm{kg}$ and $40 \mathrm{mg} / \mathrm{kg}$ ) (Abdel-Raheem et al. 2015), respectively one hour before testosterone injection. Seventy two hours after the last testosterone injection, Rats were sacrificed and the prostates were immediately removed and weighed then the prostate index was calculated. Sections of the ventral prostate lobe were fixed in $10 \%$ neutral buffered formalin and embedded in paraffin for histological examination.

\section{Prostate weight and the prostate index}

Prostate index of each rat which is the ratio between the prostate weight and the body weight was calculated after the prostate tissues were dissected and weighed.

\section{Histopathological examination}

Histopathological examination by light microscopy, ventral prostate tissues were embedded in $10 \%$ formalin and processed for paraffin sections of $4 \mu \mathrm{m}$ thickness. After de-waxing and rehydration, sections were stained with haematoxylin and eosin (H\&E)

\section{Immunohistochemical detection of tissue $N F-k B$}

Paraffin embedded prostate tissue sections of 3 micron thickness were rehydrated first in xylene and then in graded ethanol solutions. The slides were then blocked with $1 \%$ bovine serum albumin in tris buffered saline or phosphate buffered saline ( $\mathrm{PH} \mathrm{7.4)}$ for $2 \mathrm{~h}$ as appropriate. The sections were then immune-stained with one of the following primary antibodies; rabbit polyclonal IgG to rat NF-kB p65 (Santa cruz Biotech, inc., USA) at a concentration of $1 \mathrm{mg} / \mathrm{ml}$ in tris buffered saline. After washing the slides with the appropriate buffer, the sections were incubated with goat anti-rabbit IgG secondary antibody. Sections were then washed again and incubated for 5-10 min in a solution of $0.02 \%$ di-amino-benzidine containing $0.01 \% \mathrm{H} 2 \mathrm{O} 2$. Counter staining was performed using hematoxylin, and the slides were visualized under a light microscope. The quantification of NF-kB staining was performed by using Leica MDLSD image analysis software. It was represented as the optical density of stained sections per field. (Buchwalow \& Böcker 2010).

\section{Statistical analysis}

Data are presented as mean \pm SD. Multiple comparisons were performed using one-way ANOVA followed by Tukey-Kramer as a post hoc test. The 0.05 level of probability was used as the criterion for significance. All statistical analyses were performed using GraphPad Instat software version 3.

\section{Results}

\section{Prostate weight and Prostate index}

Animals treated with testosterone showed a significant increase in prostate weight and prostate weight/body weight ratio by $95.8 \%$ and $146.7 \%$, respectively compared to the control group. In comparison with the testosterone-treated group, irbesartan (10 and $20 \mathrm{mg} / \mathrm{kg}$ ) had no significant decrease in the prostate weight and prostate weight/body weight ratio. However, treatment with irbesartan at a dose of 40 
$\mathrm{mg} / \mathrm{kg}$ decreased the prostate weight and prostate weight/body weight ratio to 31.04 and $35.1 \%$, respectively compared to testosterone treated group. In addition, prostate weights of animals treated with irbesartan $(40 \mathrm{mg} / \mathrm{kg})$ were significantly lower than those in the groups of irbesartan (10 and $20 \mathrm{mg} / \mathrm{kg})$ (Table 1).

Table 1.

Effect of irbesartan treatment in three different doses $(10 \mathrm{mg} / \mathrm{kg}, 20 \mathrm{mg} / \mathrm{kg}, 40 \mathrm{mg} / \mathrm{kg}$, orally, for 4 weeks) on the prostate weight and prostate weight/body weight (prostate index) in testosterone-induced BPH rat model.

\begin{tabular}{|c|c|c|c|c|c|}
\hline Groups & Control & $\begin{array}{l}\text { Testostero } \\
\text { ne } \\
(3 \mathrm{mg} / \mathrm{kg})\end{array}$ & \begin{tabular}{|cc} 
& Test.+ \\
& esartan \\
Irb & $(10$ \\
$\mathrm{mg} / \mathrm{kg})$
\end{tabular} & $\begin{array}{c}\text { Test.+ } \\
\text { Irbesartan } \\
(20 \mathrm{mg} / \mathrm{kg})\end{array}$ & $\begin{array}{l}\text { est.+Irbesartan } \\
(40 \mathrm{mg} / \mathrm{kg})\end{array}$ \\
\hline $\begin{array}{c}\text { Prostate } \\
\text { weight }(\mathrm{g})\end{array}$ & $\begin{array}{l}0.24 \pm \\
0.05\end{array}$ & $0.47 \pm 0.06^{\mathrm{a}}$ & $0.49 \pm \frac{\mathrm{a}}{0.06}$ & $0.48 \pm \frac{a}{a} 0.14$ & $0.32 \pm 0.04^{b}$ \\
\hline $\begin{array}{c}\text { The } \\
\text { prostate } \\
\text { index }(\%)\end{array}$ & $0.15 \pm 0.04$ & $0.37 \pm 0.03^{\mathrm{a}}$ & $0.37 \underset{\mathrm{a}}{ \pm} 0.08$ & $0.36 \pm \frac{a}{a} 0.06$ & $0.24 \pm 0.03^{b}$ \\
\hline
\end{tabular}

Data are represented by mean $\pm \mathrm{SD}(n=8)$. a, $\mathrm{b}$ : statistically significant from control or testosterone respectively at $P<0.05$ using one-way ANOVA followed by TukeyKramer as a post hoc test.

\section{Histopathological examination}

Control group Section from the ventral prostates stained with hematoxylin-eosin showed no histological alteration in the acini or the lining epithelium. Epithelial cells were cuboidal in shape and of regular size (Fig. 1A). While the testosterone-injected group showed disrupted morphology in the prostate; marked thickening and hypertrophy as well as hyperplasia with polyps formation in the lining epithelium of the acini (Fig. 1B). Widening of the lumen diameter was also observed for this group. Groups treated with 10 and $20 \mathrm{mg} / \mathrm{kg}$ irbesartan showed non-significant change in the hypertrophy and hyperplasia that was induced in the lining epithelium \& as well the decrease in the epithelial thickness was insignificant too compared to testosteroneinduced group (Figs. 1C and 1D). Nevertheless, irbesartan in the dose of $40 \mathrm{mg} / \mathrm{kg}$ showed effective reduction in the hypertrophy and hyperplasia seen in the testosterone treated group preserving the normal histological structure. (Figs. 1E).

Figure 1.

Histological examination of hematoxylin-eosin sections of rat ventral prostates. A: Section taken from the prostate of the control group shows normal morphological structure of the lining epithelial cells. B: Section taken from the prostate of testosterone only treated group exhibit hypertrophy with increased epithelial thickness and polyps formation. C and D: Section taken from the prostate of the group treated with testosterone and $10 \mathrm{mg} / \mathrm{kg} \& 20 \mathrm{mg} / \mathrm{kg}$ irbesartan shows no reduction in epithelial thickness. E: Section taken from the prostate of testosterone groups co-treated with 40 
$\mathrm{mg} / \mathrm{kg}(\mathrm{F})$ irbesartan show marked reduction in prostate hypertrophy and hyperplasia induced by testosterone.

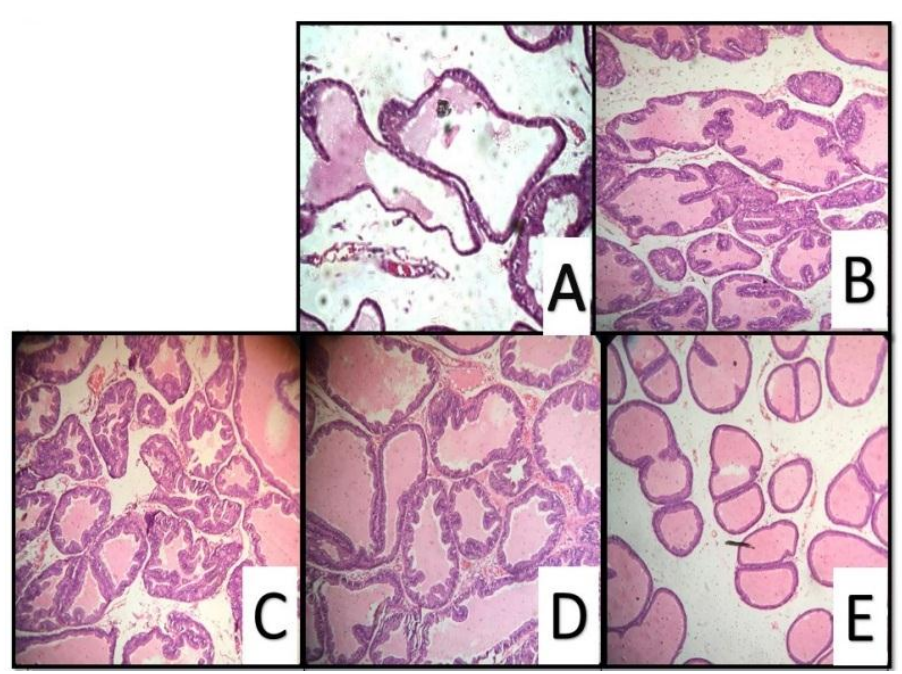

Nuclear factor kappa-B (p65)

The activated p65 subunit of NF-kB was detected immunohistochemically showing minimal expression in the specimen taken from the control group (Fig. 2A). As expected, testosterone only treated group showed significant increase in NF-kB expression compared to that of the control group manifested by intense brown staining in prostate tissues (Fig. 2B). The groups treated with irbesartan doses (10 and 20 $\mathrm{mg} / \mathrm{kg}$, respectively) showed significant increase in the NF-kB expression compared to that of the control group (Figs. 2C and 2D). Finally, the treatment of rats with irbesartan $(40 \mathrm{mg} / \mathrm{kg})$ succeeded at showing significant protection against testosterone induced expression of NF-kB to a level similar to that of the control group (Fig. 2E).

\section{Figure 2.}

Immunohistochemical staining of nuclear factor-кB (NF-кB). A: Section from the prostate of the control rats revealing a minimal degree of $\mathrm{NF}-\kappa \mathrm{B}$ expression. B:

Section from prostate of testosterone alone-treated group revealing an intensive degree of NF- $\kappa \mathrm{B}$ expression (brown stain). C\&D : Sections from prostate of the group cotreated with both testosterone and Irbesartan $(10$ and $20 \mathrm{mg} / \mathrm{kg})$ revealing an intensive degree of NF- $\kappa$ B expression (brown stain). E: Section from prostate taken from the group co-treated with both testosterone \& Irbesartan $(40 \mathrm{mg} / \mathrm{kg})$ revealing a minimal degree of NF- $\kappa \mathrm{B}$ expression. 


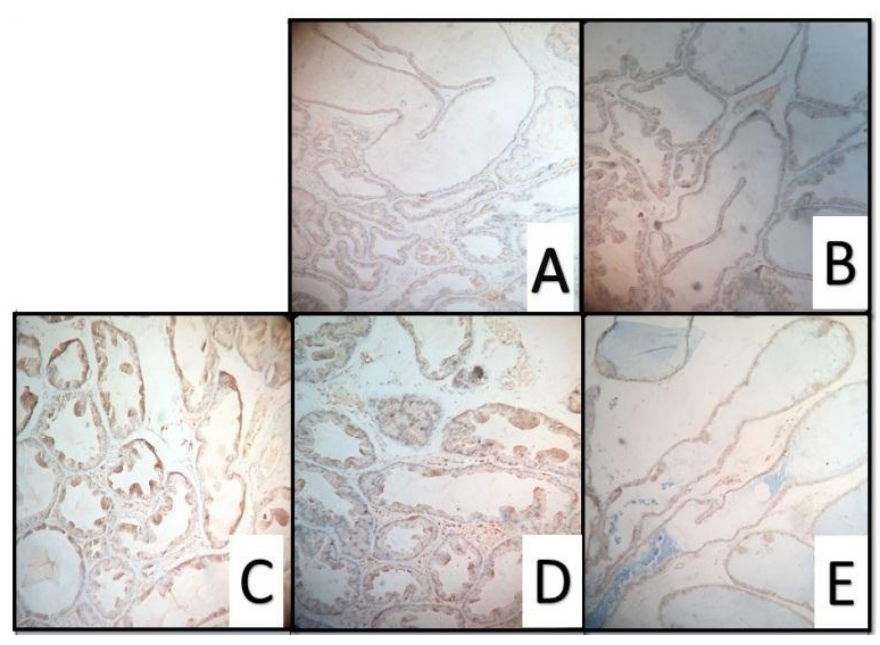

\section{Discussion:}

Benign prostatic hyperplasia is uncontrolled growth of the prostate (Maggi et al. 1989). It occurs commonly in elderly men, with an estimated prevalence of up to $85 \%$. Benign prostatic hyperplasia is characterized by lower urinary tract symptoms like urinary frequency, urgency, weak and intermittent stream, a sense of incomplete emptying and nocturia and can lead to complications including acute urinary retention, obstructive uropathy and urinary tract infection (Thiyagarajan et al. 2002).

BPH was induced in rats via repeated injections of testosterone over 4 weeks. Several studies showed that s.c. injection of rats with $3 \mathrm{mg} / \mathrm{kg}$ testosterone leads to an enlargement of the prostate sharing common features with human BPH (Scolnik et al. 1994.; Ali et al. 2013) including also epithelial hyperplasia, increased prostate weight and induced histopatholagical alterations in the prostate with an increase in epithelial thickness and intraluminal projections in rats (Woerly et al. 2003; Erbe et al. 2006). It was proposed that human $\mathrm{BPH}$ is mainly a disease of epithelial origin characterized by proliferative epithelial cells and this supports the use of testosterone in the induction of $\mathrm{BPH}$.

Indeed, the over-expression of pro-inflammatory mediators in prostate tissues pathogenesis was shown to be critically involved in the pathogenesis of BPH. Nuclear factor-kappa B is a heterodimer, composed of p50 and p65 subunits of the Rel protein family (Chiarelli et al. 2005). Several physiological and pathological conditions such as infection, inflammation and particularly, oxidative stress contributes to the activation of NF-kB (Cimino et al. 2014). The activated NF-kB (p65) subunit is involved in several stages of the inflammatory-proliferative process by regulating a number of genes, including cell adhesion molecules, growth factors, inflammatory cytokines and chemokines (Baeuerle \& Henkel 1994).

It is well known that irbesartan can block the effect of Ang II, which causes majority of the well-known physiological processes, via specific, selective noncompetitive antagonism of AT1 receptors (Schiffrin et al. 2002). There is no doubt that irbesartan can provide good 24-h blood-pressure control and improve left atrium volume in patients with mild to moderate hypertension (Degirmenci et al. 2014; Doehner et al. 2012). It has been known irbesartan brought positive results to patients 
with heart failure (Dol et al. 2001). Several studies have also confirmed that irbesartan could suppress the inflammatory components and even platelets aggregation, which attenuate the atherosclerotic processes (Li et al. 2000).

Considering the above, it's hypothesized that treatment with a compound that decreases inflammation would prevent the occurrence and progression of $\mathrm{BPH}$.

In the present study, BPH was induced by the injection of testosterone enanthate as confirmed by histopathological examination, and treatment of rats with $40 \mathrm{mg} / \mathrm{kg}$ irbesartan orally for 4 weeks significantly inhibited testosterone-mediated increase in the prostate weight, prostate weight/body weight as compared to the lower doses (10 and $20 \mathrm{mg} / \mathrm{kg}$ ). Our findings revealed that irbesartan, at a dose of $40 \mathrm{mg} / \mathrm{kg}$, was effective in countering testosterone-induced inflammation as evidenced by significantly decreasing the expression of NF-kB. Therefore, it is suggested that the reduction in prostate weight after the administration of irbesartan might be due to the antiinflammatory activity of irbesartan.

Moreover, as it was revealed before that irbesartan treatment suppressed the activation of inflammatory markers as (NF- $\kappa \mathrm{B})$ (Watanabe et al. 2016). Ang II induces the activation of NF- $\mathrm{KB}$ (Siddesha et al. 2013), These Ang II-induced responses become the contributing factor for inflammation and fibrosis in the endorgan damage (Siddesha et al. 2013). Moreover, the enhancement of oxidative stress and inflammation, including the activation of NF- $\kappa \mathrm{B}$, is induced by RAS activation (Ogawa et al. 2012). Therefore, we speculate that the anti-inflammatory effects of irbesartan result from the inhibition of the activation of NF- $\kappa \mathrm{B}$.

\section{Conclusion}

The concomitant administration of irbesartan to rats during the induction of BPH resulted in a reduction in prostate weight and inflammation in the dose of $(40 \mathrm{mg} / \mathrm{kg})$, where the attenuation of NF-kB expression in prostatic tissue played a major role. Irbesartan is a promising agent has the potential to improve current $\mathrm{BPH}$ treatments.

\section{Conflict of Interests}

The authors declare that there is no conflict of interests regarding the publication of this paper.

\section{Acknowledgements:}

DR. Adel Bakir who helped us a lot in analyzing the differences between the 3 doses by the $(H \& E)$ process and for choosing the best dose. 


\section{REFERENCES}

Abdel-Raheem, I.T., Omran, G.A. \& Katary, M.A., 2015. Irbesartan, an angiotensin II receptor antagonist, with selective PPAR-gamma-modulating activity improves function and structure of chemotherapy-damaged ovaries in rats. Fundamental \& Clinical Pharmacology, 29(3), pp.286-298.

Ali, M.I., Kondreddi, H.D.P. \& Veeresh, B., 2013. Protective effect of 2-hydroxy-4methoxy benzoic acid on testosterone induced benign prostatic hyperplasia in Wister rats. European Journal of Pharmacology, 698(1-3), pp.397-403.

Arruzazabala, M. de L. et al., 2007. Effects of coconut oil on testosterone-induced prostatic hyperplasia in Sprague-Dawley rats. Journal of Pharmacy and Pharmacology, 59(7), pp.995-999.

Baeuerle, P.A. \& Baltimore, D., 1996. NF-kappa B: ten years after. Cell, 87(1), pp.13-20.

Baeuerle, P.A. \& Henkel, T., 1994. Function and Activation of NF-kappaB in the Immune System. Annual Review of Immunology, 12(1), pp.141-179.

Barak, Y. et al., 1999. PPAR gamma is required for placental, cardiac, and adipose tissue development. Molecular cell, 4(4), pp.585-595.

Barry, M.J., 2001. Evaluation of symptoms and quality of life in men with benign prostatic hyperplasia. Urology, 58(6 Suppl 1), p.25-32; discussion 32.

Buchwalow, I.B. \& Böcker, W., 2010. Probes Processing in Immunohistochemistry. In Immunohistochemistry: Basics and Methods. Berlin, Heidelberg: Springer Berlin Heidelberg, pp. 19-29.

Chiarelli, F. et al., 2005. Effects of irbesartan on intracellular antioxidant enzyme expression and activity in adolescents and young adults with early diabetic angiopathy. Diabetes care, 28(7), pp.1690-7.

Cimino, S. et al., 2014. Oxidative stress and body composition in prostate cancer and benign prostatic hyperplasia patients. Anticancer research, 34(9), pp.5051-6.

Degirmenci, H. et al., 2014. Assessment of effect of irbesartan and nebivolol on the left atrium volume and deformation in the patients with mild-moderate hypertension. European review for medical and pharmacological sciences, 18(6), pp.781-789.

Doehner, W. et al., 2012. Improved insulin sensitivity by the angiotensin receptor antagonist irbesartan in patients with systolic heart failure: A randomized double-blinded placebo-controlled study. International Journal of Cardiology, 161(3), pp.137-142.

Dol, F. et al., 2001. Angiotensin AT1 receptor antagonist irbesartan decreases lesion size, chemokine expression, and macrophage accumulation in apolipoprotein E-deficient mice. Journal of cardiovascular pharmacology, 38(3), pp.395405.

Erbe, D. V. et al., 2006. Molecular activation of PPAR $\gamma$ by angiotensin II type 1receptor antagonists. Vascular Pharmacology, 45(3), pp.154-162.

Fabiani, M.E. et al., 2001. Angiotensin II enhances noradrenaline release from 
sympathetic nerves of the rat prostate via a novel angiotensin receptor: implications for the pathophysiology of benign prostatic hyperplasia. The Journal of endocrinology, 171(1), pp.97-108.

Fujii, J. et al., 2003. Cooperative function of antioxidant and redox systems against oxidative stress in male reproductive tissues. Asian journal of andrology, 5(3), pp.231-242.

Hoesel, B. \& Schmid, J.A., 2013. The complexity of NF- $\mathrm{BB}$ signaling in inflammation and cancer. Molecular Cancer, 12(1), p.86.

Jiang, M. et al., 2010. Disruption of PPAR $\gamma$ signaling results in mouse prostatic intraepithelial neoplasia involving active autophagy. Cell Death and Differentiation, 17(3), pp.469-481. Johnston, C.I., 1990. Biochemistry and pharmacology of the renin-angiotensin system. Drugs, 39 Suppl 1, pp.21-31.

Li, P. et al., 2000. Novel angiotensin II AT(1) receptor antagonist irbesartan prevents thromboxane $\mathrm{A}(2)$-induced vasoconstriction in canine coronary arteries and human platelet aggregation. The Journal of pharmacology and experimental therapeutics, 292(1), pp.238-46.

Maggi, C.A. et al., 1989. Infravesical outflow obstruction in rats: a comparison of two models. General pharmacology, 20(3), pp.345-9.

Nicholls, M.G., Richards, A.M. \& Agarwal, M., 1998. The importance of the reninangiotensin system in cardiovascular disease. Journal of human hypertension, 12(5), pp.295-9.

O'Malley, K.J. et al., 2009. The expression of androgen-responsive genes is upregulated in the epithelia of benign prostatic hyperplasia. The Prostate, 69(16), pp.1716-23.

Ogawa, M. et al., 2012. Impaired post-infarction cardiac remodeling in chronic kidney disease is due to excessive renin release. Laboratory Investigation, 92(12), pp.1766-1776.

Oh, S.-J., 2013. Unsolved issues in managing benign prostatic hyperplasia. Korean journal of urology, 54(6), pp.349-50.

Paolone, D.R., 2010. Benign Prostatic Hyperplasia. Clinics in Geriatric Medicine, 26(2), pp.223-239.

Pawlicki, B., Zieliński, H. \& Dabrowski, M., 2004. [Role of apoptosis and chronic prostatitis in the pathogenesis of benign prostatic hyperplasia]. Polski merkuriusz lekarski: organ Polskiego Towarzystwa Lekarskiego, 17(100), pp.307-310.

Peach, M.J., 1977. Renin-angiotensin system: biochemistry and mechanisms of action. Physiological reviews, 57(2), pp.313-370.

Roehrborn, C.G., 2011. Male Lower Urinary Tract Symptoms (LUTS) and Benign Prostatic Hyperplasia (BPH). Medical Clinics of North America, 95(1), pp.87100.

Rosen, E.D. \& Spiegelman, B.M., 2001. PPAR : a Nuclear Regulator of Metabolism, Differentiation, and Cell Growth. Journal of Biological Chemistry, 276(41), 
pp.37731-37734.

Schiffrin, E.L., Park, J.B. \& Pu, Q., 2002. Effect of crossing over hypertensive patients from a beta-blocker to an angiotensin receptor antagonist on resistance artery structure and on endothelial function. Journal of hypertension, 20(1), pp.71-78.

Scolnik, M.D., Servadio, C. \& Abramovici, A., Comparative study of experimentally induced benign and atypical hyperplasia in the ventral prostate of different rat strains. Journal of andrology, 15(4), pp.287-97.

Shappell, S.B. et al., 2001. 15S-Hydroxyeicosatetraenoic acid activates peroxisome proliferator-activated receptor gamma and inhibits proliferation in PC3 prostate carcinoma cells. Cancer research, 61(2), pp.497-503.

Shappell, S.B. et al., Alterations in lipoxygenase and cyclooxygenase- 2 catalytic activity and mRNA expression in prostate carcinoma. Neoplasia (New York, N.Y.), 3(4), pp.287-303.

Siddesha, J.M. et al., 2013. Angiotensin II stimulates cardiac fibroblast migration via the differential regulation of matrixins and RECK. Journal of Molecular and Cellular Cardiology, 65, pp.9-18.

Standiford, T.J., Keshamouni, V.G. \& Reddy, R.C., 2005. Peroxisome Proliferatoractivated Receptor- as a Regulator of Lung Inflammation and Repair. Proceedings of the American Thoracic Society, 2(3), pp.226-231.

Thiyagarajan, M., Kaul, C.L. \& Ramarao, P., 2002. Enhancement of alphaadrenoceptor-mediated responses in prostate of testosterone-treated rat. European journal of pharmacology, 453(2-3), pp.335-344.

Tontonoz, P., Hu, E. \& Spiegelman, B.M., 1994. Stimulation of adipogenesis in fibroblasts by PPAR gamma 2, a lipid-activated transcription factor. Cell, 79(7), pp.1147-1156.

Watanabe, R. et al., 2016. Angiotensin II receptor blocker irbesartan attenuates cardiac dysfunction induced by myocardial infarction in the presence of renal failure. Hypertension Research, 39(4), pp.237-244.

Woerly, G. et al., 2003. Peroxisome proliferator-activated receptors alpha and gamma down-regulate allergic inflammation and eosinophil activation. The Journal of experimental medicine, 198(3), pp.411-421.

Youn, D.-H. et al., 2017. Chrysophanic acid reduces testosterone-induced benign prostatic hyperplasia in rats by suppressing $5 \alpha$-reductase and extracellular signal-regulated kinase. Oncotarget, 8(6), pp.9500-9512. 
"دراسة توضح تأثير الأربيسارتان في علاج تضخم البروستاتا الحميد"

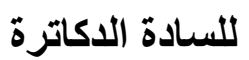

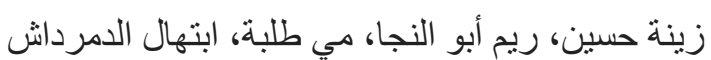

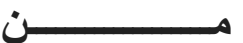

قسم الصيدلة و علم السموم، كلية الصيدلة، جامعة عين شمس، العباسية، القاهرة، مصر

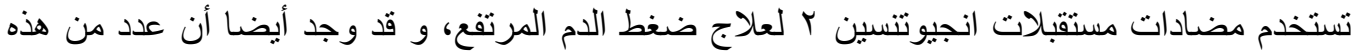

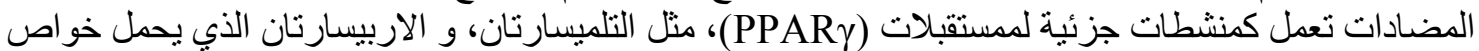
مضادة للالتهاب.

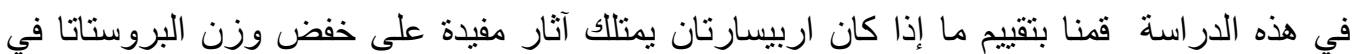

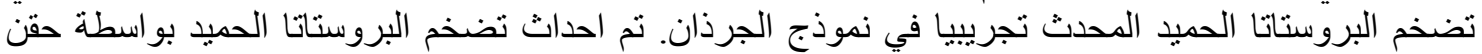

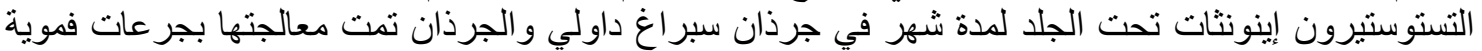

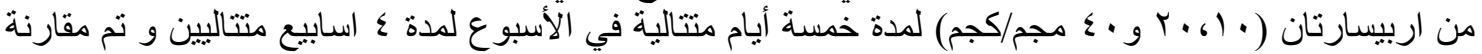

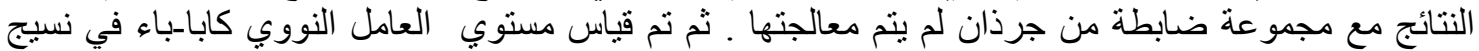

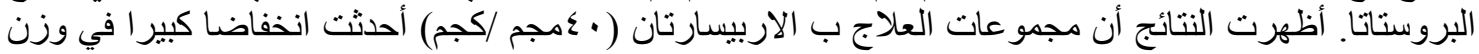

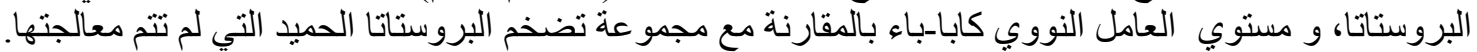

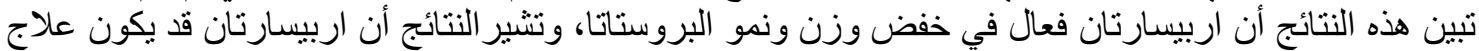

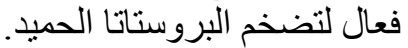

